\title{
Empirical molecular modelling of crystal growth modifiers
}

\author{
F. Jones, A. L. Rohl
}

AJ Parker CRC for Hydrometallurgy, Nanochemistry Research Institute, Curtin University of Technology, GPO Box U1987, Perth WA 6845 Australia.

Phone: +6189266 $7677 \quad$ Fax: +6189266 4699

email: franca@power.curtin.edu.au

\begin{abstract}
Molecular modelling has been successfully used to interpret the effect of two molecules on the crystal growth of barium sulfate. The replacement energy was found to correlate with the degree of inhibition as determined from conductivity experiments. It was also able to predict the preferred barium sulfate face for additive adsorption. For EDTP (ethylenediaminetetramethylenephosphonic acid), the energetically favoured adsorption configurations were those where the phosphonate groups occupied vacant sulfate lattice sites, whilst for EDTA (ethylenediaminetetraacetic acid) it was generally not possible for all the carboxylate groups to lie within the surface and so surface barium cation to additive oxygen interactions became important. Whether in the surface or above it, the number of Ba$\mathrm{O}_{\text {modifier }}$ interactions were important in making adsorption of the modifier energetically favourable.
\end{abstract}

KEYWORDS: molecular modelling, barium sulfate, crystal modifiers, adsorption, precipitation

PACS Codes: 81.10.Dn, 68.08.De, 68.43.-h, 68.43.Fg, 82.20.Wt 


\section{INTRODUCTION}

The formation of nanoparticles often involves the use of organic additives that modify the precipitation thermodynamics and/or kinetics of various materials $(1,2)$. At the Nanochemistry Research Institute, we have several model systems currently under investigation. One of these is the barium sulfate system, so chosen because of its widespread occurrence as a scale compound $(3,4)$. It is also a useful nanoparticle model system as described in (5 - 7). The work undertaken has combined the results from laboratory experiments with those from molecular modelling simulations utilising empirical potentials, to try and understand the mode of action of the growth modifiers.

In this paper, we present both experimental precipitation data and molecular modelling calculations on two organic molecules known to inhibit barium sulfate precipitation. The two molecules chosen are EDTA and EDTP (Figure 1). The differences observed in the way they interact with barium sulfate will give insight into how their differing functional groups interact with the surfaces of barium sulfate as the scaffolding holding the functional groups of the two molecules is identical. There are two significant differences between the carboxylic acid and phosphonic acid functional groups used here; their stereochemistry and charge.

Figure 1 near here

\section{METHODS}

Experimental

The nephelometry and conductivity experiments have been described in detail 
elsewhere (8) and so will only be briefly dealt with here. Non-seeded, desupersaturation curves were obtained in a thermostatted vessel kept at a temperature of $25{ }^{\circ} \mathrm{C}$ using a conductivity meter (WTW LF 197 Conductivity meter) to monitor precipitation in situ. An overhead stirrer kept the solids in suspension (150 rpm). The method consisted of equilibrating $200 \mathrm{ml}$ MilliQ water with $0.5 \mathrm{ml}, 100 \mathrm{mM} \mathrm{BaCl} 2$ ( $\mathrm{Ba}^{2+}$ concentration $0.249 \mathrm{mM}$ after addition). The conductivity meter values were logged onto a computer. Equivalent $\mathrm{Na}_{2} \mathrm{SO}_{4}(0.5 \mathrm{ml}, 100 \mathrm{mM})$ was added to commence the reaction. The graph of conductivity versus time was used to calculate the observed growth rate (kobs) by fitting the linear region of the de-supersaturation curve. The pH was 5.6 for all the experiments. Reproducibility of the experiments showed a $10 \%$ error in the de-supersaturation rate in the linear region and a larger variation in the induction time of $\sim 20 \%$. A nephelometer probe (Analite NEP 160 from McVan Instruments) which utilises a $90^{\circ}$ detector was used in turbidity experiments. The barium chloride concentration, sodium sulfate concentration and temperature were the same as for the conductivity experiments. The stirring rate was increased to $300 \mathrm{rpm}$ to ensure that particles were detected by the probe. The errors for this method were found to be similar to those for the conductivity experiments.

\section{Molecular Modelling}

All of the molecular modelling work used empirically derived potentials.

Barium sulfate

The parameters for the various potentials describing barium sulfate were initially taken from Allen et al. (9) [model 2] and were subsequently refined using GULP (10) 
to best match the known crystal structures of the iso-structural pair of strontium and barium sulfate. These derived potentials are listed in the Appendix, section A

Using these potentials, the barium and strontium sulfate lattice parameters were calculated and matched the experimental cell parameters and volumes to within $1 \%$. Additionally, elastic constants, bulk modulus, compressibility and density calculated with these potentials, were compared to literature values and were found to be in reasonable agreement.

GULP and MARVIN (11) were used to minimise the energy of surface structures. They both use a simulation cell, which is split into two regions. Region I contains the surface atoms and these are allowed to relax while Region II contains sufficient atoms to reproduce the effect of the bulk properties on Region I and remains fixed. In all calculations, the Region I was at least six sulfate layers thick. The (100) surface was found to have two possible terminations of very similar surface energy. Thus, both are investigated in this work. The (100b) surface is flat containing both barium and sulfate ions. The (100a) surface is the (100b) surface with half of the barium and sulfate surface rows removed.

The next stage in the simulation is to calculate the morphology of barium sulfate from the surface and attachment energies (as defined in reference 11) The morphology derived from the surface energies is termed the 'equilibrium' morphology, whilst that derived from the attachment energy is the 'growth' morphology (11). Each face can be cut along various planes parallel to the desired surface, producing different surface terminations and all must be minimised to find the most stable one. In order to be sure 
that the most important morphological faces are found, the fifteen faces with the largest interplanar spacings were simulated. The calculated morphologies, shown in Figure 2, were generated via the Wulff plot (12) using GDIS (13).

Figure 2 near here

\section{Additives}

Due to the complex nature of their protonation states, which involves the formation of zwitterions (14), all calculations used the fully ionised molecules. This has the drawback that it does not investigate the possible interaction of the protonated nitrogen with the surface but is a worthwhile first approximation. The potentials and parameters for these molecules were the same as those used by Wilson (15) and Fogg et al., (16). Briefly, these potentials were derived from CVFF in InsightII (17), whilst the charges were obtained from Spartan (18) via fitting to the electrostatic potential from a PM3 (19) optimisation run. Potentials, however, were also required for the interatomic interaction of these molecules with the barium sulfate surface and these were obtained from the ESFF forcefield (20). The interatomic potential parameters used are listed in the Appendix, section B. For all the additives studied, various starting configurations and sulfate vacancies were investigated in order to find the lowest energy configurations. As an added measure, minimisations were conducted firstly in a two-stage process whereby the additive was docked while the surface Region I was kept fixed and then allowing the whole to relax; secondly the additives were docked with Region I relaxing simultaneously in a single stage minimisation. 
Solvation energies

Solvation energies were calculated with the COSMO code within GULP using the dielectric constant of water (78.4). The values obtained are shown in Table 1.

Table I near here

RESULTS

Replacement Energies

The replacement energy (21) was used to determine the energetics of adsorption. The replacement energy is defined by:

$$
\Delta \mathrm{E}_{\mathrm{r}}=\left(\mathrm{E}_{\text {surf }+ \text { additive }}+\mathrm{n}\left\{\mathrm{E}_{\text {sulf }}+\mathrm{E}_{\text {solvSO4}}\right\}\right)-\left(\mathrm{E}_{\text {surf }}+\left\{\mathrm{E}_{\text {additive }}+\mathrm{E}_{\text {solvAdd }}\right\}\right)-\text { Eqn }
$$

1.

$\mathrm{E}_{\text {surf+additive }}$ is the energy of the system with the additive adsorbed, $\mathrm{n}$ is the number of sulfates removed from the surface in order to adsorb the additive, $\mathrm{E}_{\text {sulf }}$ is the energy of the isolated sulfate ion and $\mathrm{E}_{\mathrm{solvSO}}$ is the solvation energy of the sulfate, $\mathrm{E}_{\text {surf }}$ is the energy of the surface with the sulfates still in the lattice, $E_{\text {additive }}$ is the energy of the isolated additive and $\mathrm{E}_{\text {solvadd }}$ is the solvation energy of the additive. The more negative (lower) the replacement energy, the more favourable is the interaction of the organic additive with the surface in question.

The following replacement energies were obtained for the additives on each face investigated:

Table II near here 
As can be seen from these values, the replacement energy for EDTP is always lower than for EDTA being roughly twice as energetically favoured on each face. In terms of the preferred face for adsorption the two organics differ:

EDTA: $(011)>(100 a)>(010)>(210)>(101)>(001)>(100 b)>(211)$

EDTP: $(100 \mathrm{a})>(210)>(100 \mathrm{~b})>(001)>(101)>(010)>(011)>(211)$

i.e. whilst the (011) is the most favoured for EDTA, it is almost the least favoured for EDTP. However, the (210) and the (100a) faces are within the top four most favoured faces for adsorption for both additives.

\section{Adsorbed Configurations}

Figure 3 shows the adsorbed configurations of the four most energetically favoured faces for EDTP and EDTA.

Figure 3 near here

Clearly, EDTP better fits into the surface than EDTA. In all calculations, charge neutrality has been maintained. Thus, a single phosphonate group requires the removal of a sulfate ion, whereas it takes two carboxylate groups to replace a single surface sulfate ion. Therefore, for EDTA, we might expect that for each sulfate vacancy in the surface, one carboxylate will occupy the vacant site, whilst another binds to the surface. However, for many of the EDTA configurations, most of the carboxylate groups lie on top of the surface. This is even true for the (011) face, which is the most energetically favoured configuration. Closer inspection of this configuration shows that, although the carboxylate groups lie above the surface, their oxygen atoms are all within a distance to interact with at least one (and in most cases 
two) surface barium atoms. On the (011) there are a total of $13 \mathrm{Ba}-\mathrm{O}_{\text {carb }}$ distances less than $3 \AA$. The average $\mathrm{Ba}-\mathrm{O}_{\text {carb }}$ distance is $2.431 \AA$. The only EDTA configuration to show all four carboxylate groups within the surface is that on the (100a). On this surface, every second row of sulfates is missing in addition to the two sulfate vacancies (see Fig 3) and this gives a lot of space for the carboxylate groups to occupy. This probably accounts for the low replacement energy found for this surface. In contrast, many of the EDTP configurations show all four phosphonate groups embedded in the surface. Of the four most favourable replacement energies, only the (100b) surface containing EDTP shows one phosphonate group above the surface and this (like EDTA) is interacting with surface barium atoms. For the most energetically favoured face (the (100a)) there are now $22 \mathrm{Ba}-\mathrm{O}_{\text {phos }}$ distances less than $3 \AA$, with the average being $2.334 \AA$. Thus, the existence of the extra oxygen atom on the phosphonate group means that there are more interatomic Ba- $\mathrm{O}_{\text {modifier }}$ interactions and the phosphonate's ability to occupy the sulfate vacancy means that this interaction is slightly stronger (due to the shorter distance).

\section{Comparison To Experiment}

Table III near here

As can be seen in Table III, EDTA must be present at much higher concentrations to inhibit precipitation of barium sulfate to the same degree as EDTP. Thus, the replacement energy correlates with inhibition activity. Firstly, the negative replacement energy for both additives correlates with the fact that both inhibit barite 
precipitation, whilst the more negative replacement energy for EDTP correlates with its much stronger inhibition.

The resultant morphology of the particles from these experiments also correlates rather well with the modelling results for adsorption onto the various faces. EDTP was calculated to have a strong interaction with both (100) surface terminations, the (210) face and the (001) face. In Figure 4 we see that at low concentrations the (100) is clearly stabilised as is the (210) and (001) when compared to the control morphology (which consists of a small (001) face and (hk0) curved faces) whilst at higher concentrations, fibre-like bundles are formed which have been previously shown to reflect a strong interaction with the (210), (001) or (211) faces (22).

Figure 4 near here

In the case of EDTA (Figure 5), the rounded edges forming 'rice' shaped particles of barium sulfate appears to be the signature of particles with a strong interaction on the (011) as demonstrated by other phosphonate additives also calculated to have a strong interaction on the (011) (Figure 5b and refs 21 \& 23). At higher concentrations, the particles are flatter. This is also observed when barite is precipitated in the presence of a triphosphonate; in this case the flat section of the particle was shown, via selected area diffraction, to be the (100). This suggests that when EDTA is present at high concentrations, the (100) face is also affected as predicted from the molecular modelling.

Figure 5 near here 
According to the nephelometry results, both EDTA and EDTP (Figure 6) were found to prolong the induction time suggesting that they interact with the critical nuclei for precipitation. This undoubtedly impacts on the morphology observed although molecular modelling to date has not probed the interaction of these organics on small (nano) clusters.

Figure 6 near here

\section{SUMMARY AND CONCLUSIONS}

In summary, molecular modelling has been successful both in predicting the most favoured faces for interactions to occur for our crystal modifiers (EDTA and EDTP) and that the EDTP would be expected to be the better inhibitor based on the more negative replacement energy. It was found that the EDTA molecule is rarely able to adsorb with all of its carboxylate groups in the surface while the opposite is true for EDTP. However, both the (210) and (100a) faces were favourable adsorption faces for both modifiers. The ability of the functional group to occupy sulfate lattice positions appears to be a charge dominated interaction and this is the primary effect when phosphonate replaces carboxylate in the modifier. That is, the phosphonate modifier (EDTP) docks on the surface almost always with the phosphonate groups situated in vacant sulfate sites. In contrast, EDTA almost always had at least two carboxylate groups sitting just above the surface with at least one other in a sulfate lattice site. The faces with the lowest replacement energy were those where the carboxylate groups above the surface were still able to interact with surface barium atoms. 
Experimental results show that the EDTP affects both the (210) and (100) zones of barium sulfate in agreement with the calculations, whilst EDTA shows a strong interaction with the (011), which again matches our simulations. Nephelometry results show that these organic molecules interact with nucleating clusters, which will be simulated in future work.

\section{ACKNOWLEDGEMENTS}

We gratefully acknowledge that this research has been supported under the Australian Government's Cooperative Research Centre (CRC) Program, through the AJ Parker CRC for Hydrometallurgy. We'd also like to thank Prof. Julian Gale for allowing us to use a pre-release of the COSMO algorithm within GULP.

\section{REFERENCES}

1 F. Jones, M. I. Ogden, A. Oliveira, G. M. Parkinson, W. R. Richmond (2003), CrystEngComm, 5(30), 159.

2 N. I. Ivanova, D. S. Rudelev, B. D. Summ, A. A. Chalykh (2001), Colloid J., 63(6), 714.

$3 \quad$ K. S. Sorbie, E. J. Mackay (2000), J. Petroleum Sci. Eng., 27, 85.

4 W. J. Benton, I. R. Collins, I. M. Grimsey, G. M. Parkinson, S. A. Rodger (1993), Faraday Discussions, 95, 281.

5 L. Qi, H. Cölfen and M. Antonietti (2000), Chem. Mater., 12, 2392.

6 H.-C. Schwarzer W. Peukert (2002), Chem. Eng. Tehcnol., 25(6), 657.

7 D. Rautaray, A. Kumar, S. Reddy, S. R. Sainkar, M. Sastry (2002), Cryst. Growth \& Design, 2(3), 197.

8 F. Jones, A. Oliviera, G. M. Parkinson, A. L. Rohl, A. Stanley and T. Upson (2004), Journal of Crystal Growth, 262 (1-4), 572-580

9 N. L. Allan, A. L. Rohl, D. H. Gay, C. R. A. Catlow, R. J. Davey, W. C. Mackrodt, (1993), J. Chem. Soc., Faraday Discuss., 95, 273. 
10 J.D. Gale and A.L. Rohl, “The General Utility Lattice Program (GULP)”, Mol. Simulat., 29, 291-341 (2003).

11 D. H. Gay and A. L. Rohl, (1995), J. Chem. Soc., Faraday Trans., 91(5), 925.

12 G. Wulff, Z. Krystallogr. 1901, 34, 449-530.

13 S.D. Fleming and A.L. Rohl “GDIS: A Visualization Program for Molecular and Periodic Systems”, Z. Kristallogr., in press.

14 S. Westerback, K. S. Rajan and A. E. Martell (1956), Nature, 178, 321.

15 M. P. Wilson (2002), personal communication.

16 A. M. Fogg, A. J. Freij, A. L. Rohl, M. I. Ogden, G. M. Parkinson, J. Phys. Chem. B, 106, 5820-5826.

17 InsightII Version 2.3.6, Biosym Technologies Inc.: San Diego, 1995.

18 W. J. Hehre; Jianguo, Yu; P. E. Klunzinger (1997). A Guide to Molecular Mechanics and Molecular Orbital Calculations in Spartan. Wavefunction, Inc.: Irvine, CA.

19 J. J. P. Stewart (1989), J. Computational Chem., 10, 221-264.

20 S. Shi, L. Yan, Y. Yang, J. Fisher-Shaulsky and T. Thacher (2002), J. Computational Chem., 24(9), 1059.

21 A. L. Rohl, D. H. Gay, R. J. Davey, and C. R. A. Catlow (1996), J. Am. Chem. Soc., 118, 642.

L. Qi, H. Cölfen, and M. Antonietti (2000), Angew. Chem. Int. Ed., 39(3), 604. Soc. Faraday Trans, 87, 3409. 
Table I. Solvation energies obtained for the various species

$\begin{array}{ll} & \mathrm{kJ} \mathrm{mol}^{-1} \\ \mathrm{SO}_{4}{ }^{2-} & -1889.33 \\ \mathrm{EDTA}^{4-} & -2074.31 \\ \mathrm{EDTP}^{8-} & -7460.32\end{array}$

Table II. Replacement energies $\left(\mathrm{kJ} \mathrm{mol}^{-1}\right)$ found for each additive on each face

$\begin{array}{ccc}\text { FACE } & \text { EDTP } & \text { EDTA } \\ \mathbf{0 0 1} & -6130.5 & -3018.5 \\ \mathbf{2 1 0} & -6272.4 & -3142.4 \\ \mathbf{2 1 1} & -5774.2 & -2879.8 \\ \mathbf{0 1 0} & -5981.8 & -3150.6 \\ \mathbf{0 1 1} & -5898.4 & -3204.6 \\ \mathbf{1 0 1} & -6064.1 & -3041.1 \\ \mathbf{1 0 0 b} & -6188.6 & -3016.8 \\ \mathbf{1 0 0 a} & -6397.6 & -3192.5\end{array}$


Table III. De-supersaturation rate $\left(-1 \times 10^{-5} \mathrm{mS} \mathrm{s}^{-1}\right)$ measured for the precipitation of barium sulfate in the presence of EDTA and EDTP

\section{Concentration (mM) De-supersaturation rate}

0

3.34

EDTA

$\begin{array}{ll}0.016 & 2.79\end{array}$

$0.033 \quad 2.62$

$0.049 \quad 2.43$

EDTP

$\begin{array}{lc}0.0001 & 1.81 \\ 0.0005 & 0.13 \\ 0.0012 & 0.02 \\ 0.0046 & 0\end{array}$




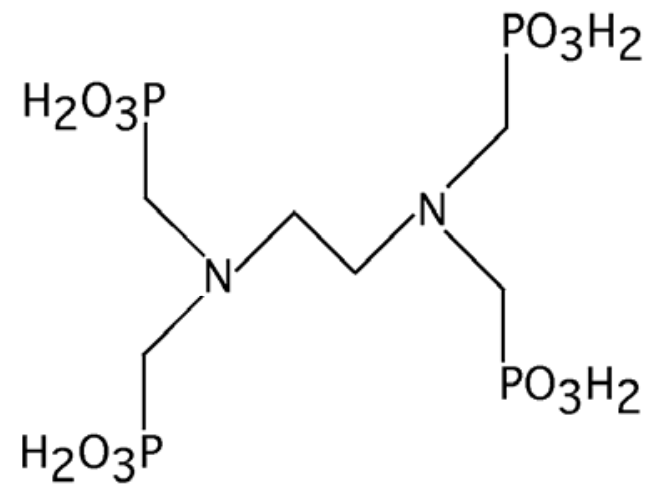

EDTP

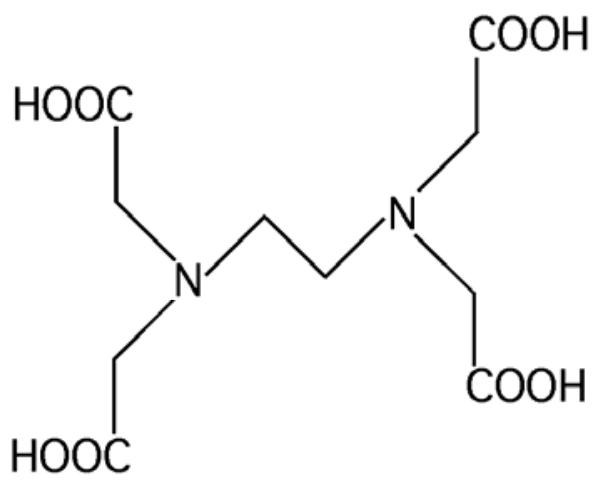

EDTA

Figure 1. Schematic diagram of the organic additives investigated in this work,

EDTP = ethylenediaminetetramethylenephosphonic acid and

EDTA = ethylenediaminetetraacetic acid 


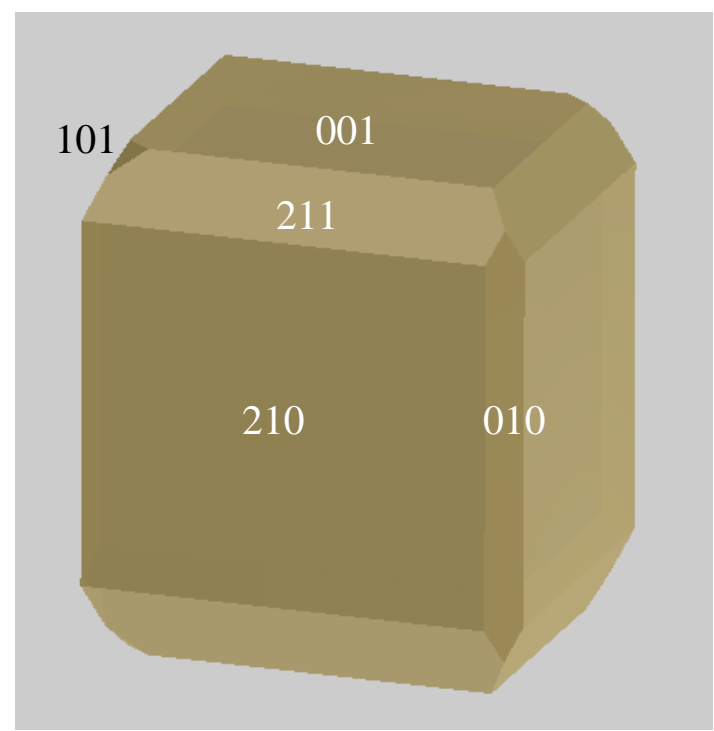

Equilibrium morphology

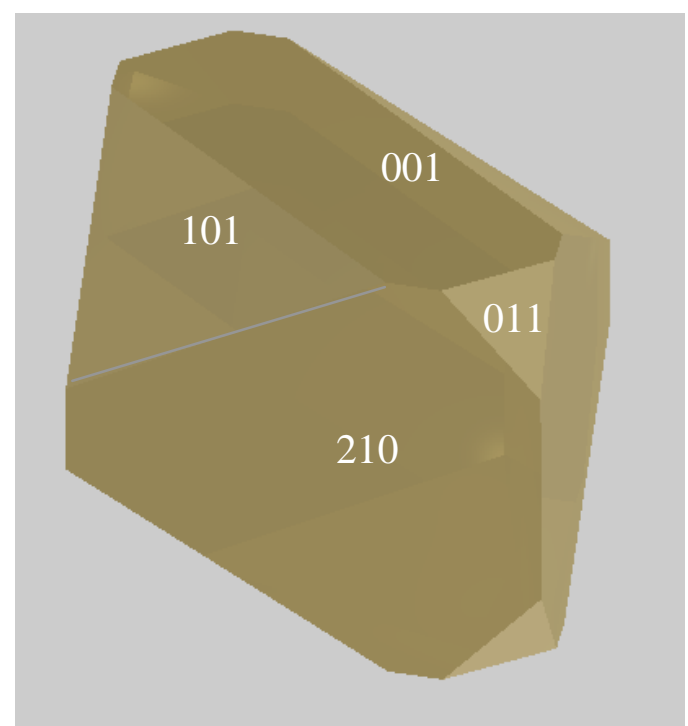

Growth morphology

Figure 2. The calculated equilibrium and growth morphologies of barium sulfate . 
EDTP: (100a)

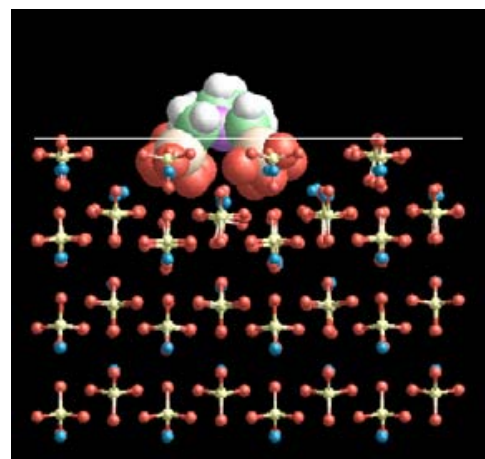

(210)

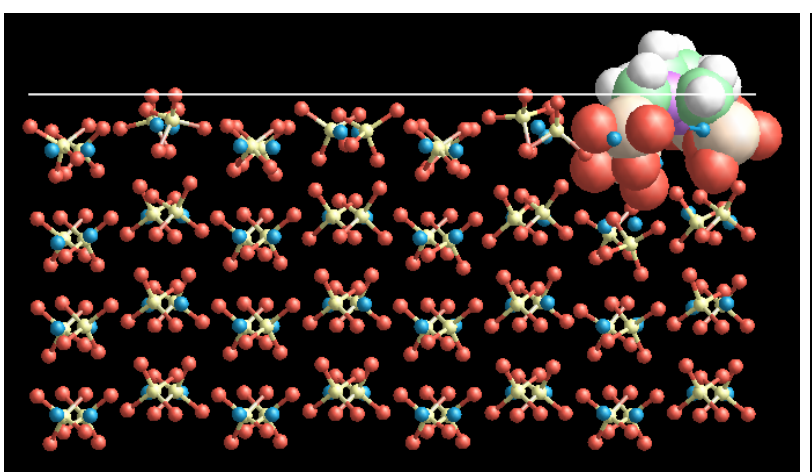

(100b)

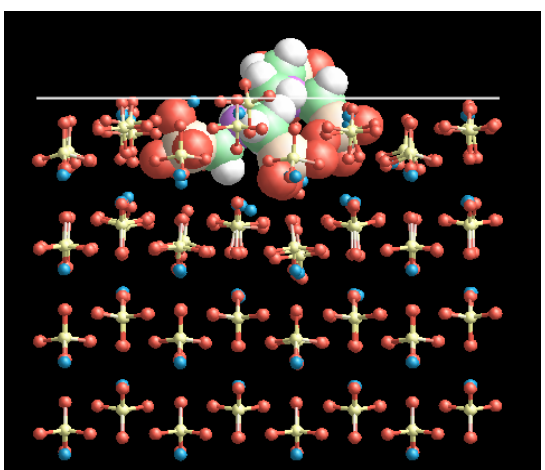

(001)

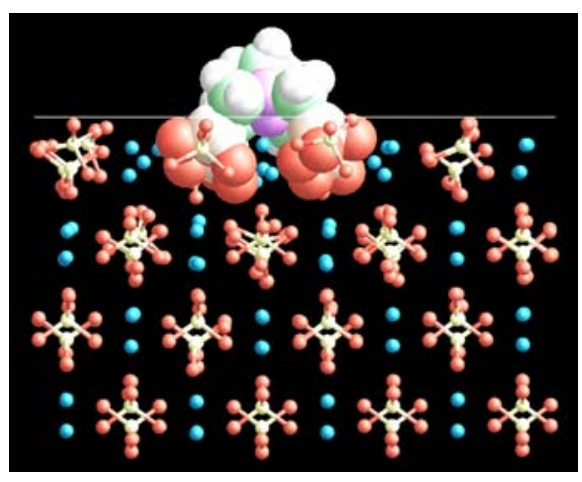

EDTA:

(011)

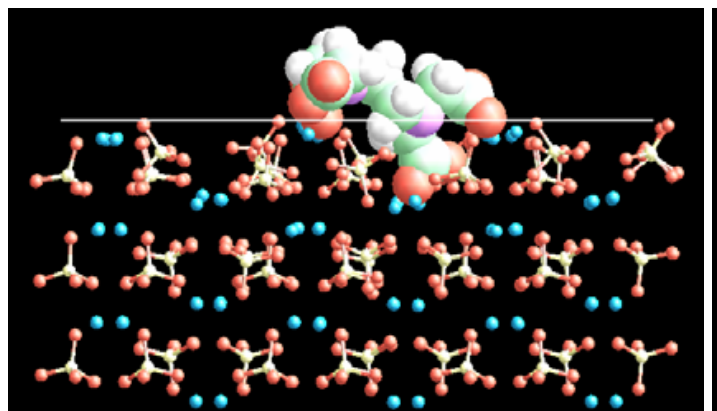

(100a)

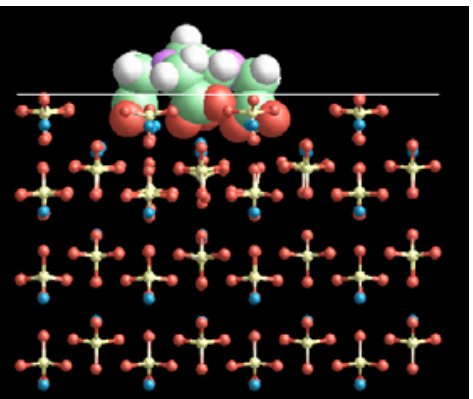

(010)

(210)

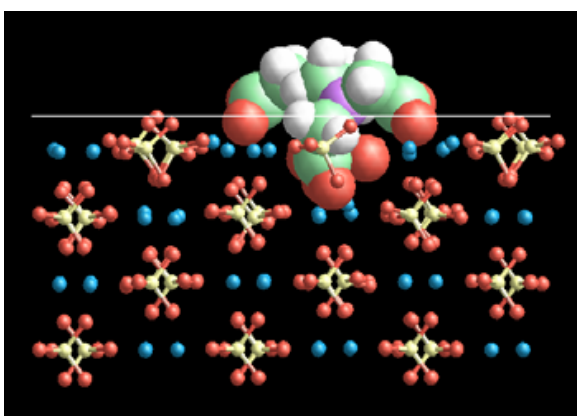

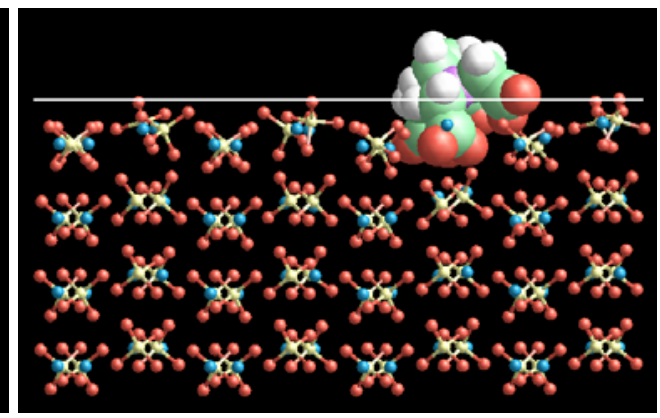




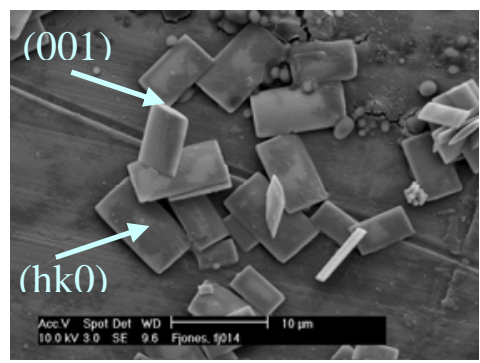

0

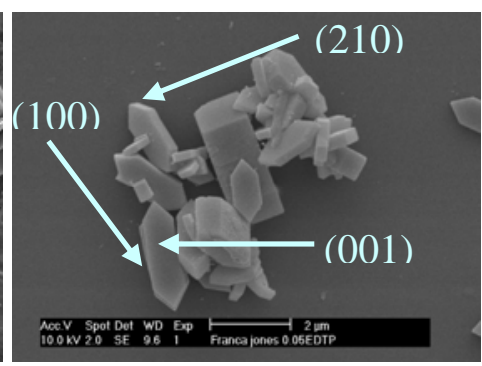

$0.0001 \mathrm{mM}$

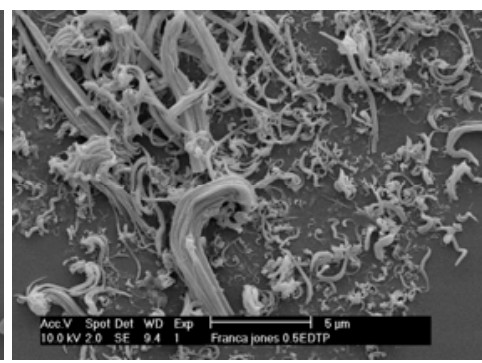

$0.0012 \mathrm{mM}$

Figure 4. SEM micrographs of barium sulfate particles formed in the presence of increasing concentrations of EDTP 


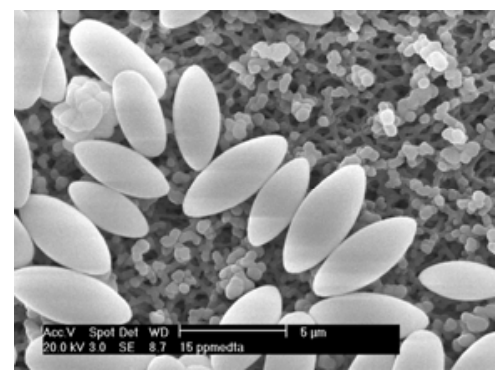

A

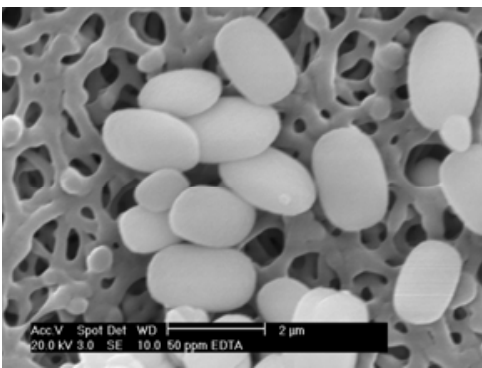

B

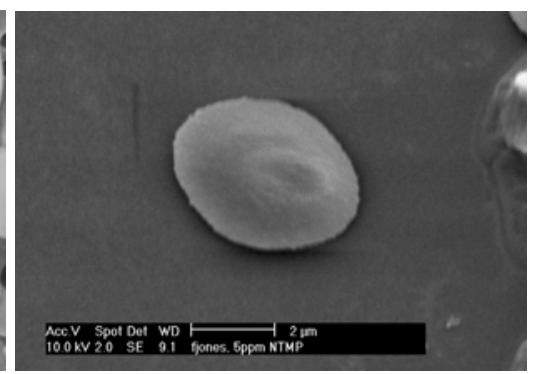

C

Figure 5. Barium sulfate particles formed in the presence of a) EDTA at $0.049 \mathrm{mM}$ and b) EDTA at $0.13 \mathrm{mM} \mathrm{c)}$ aminotrimethylenephosphonate 


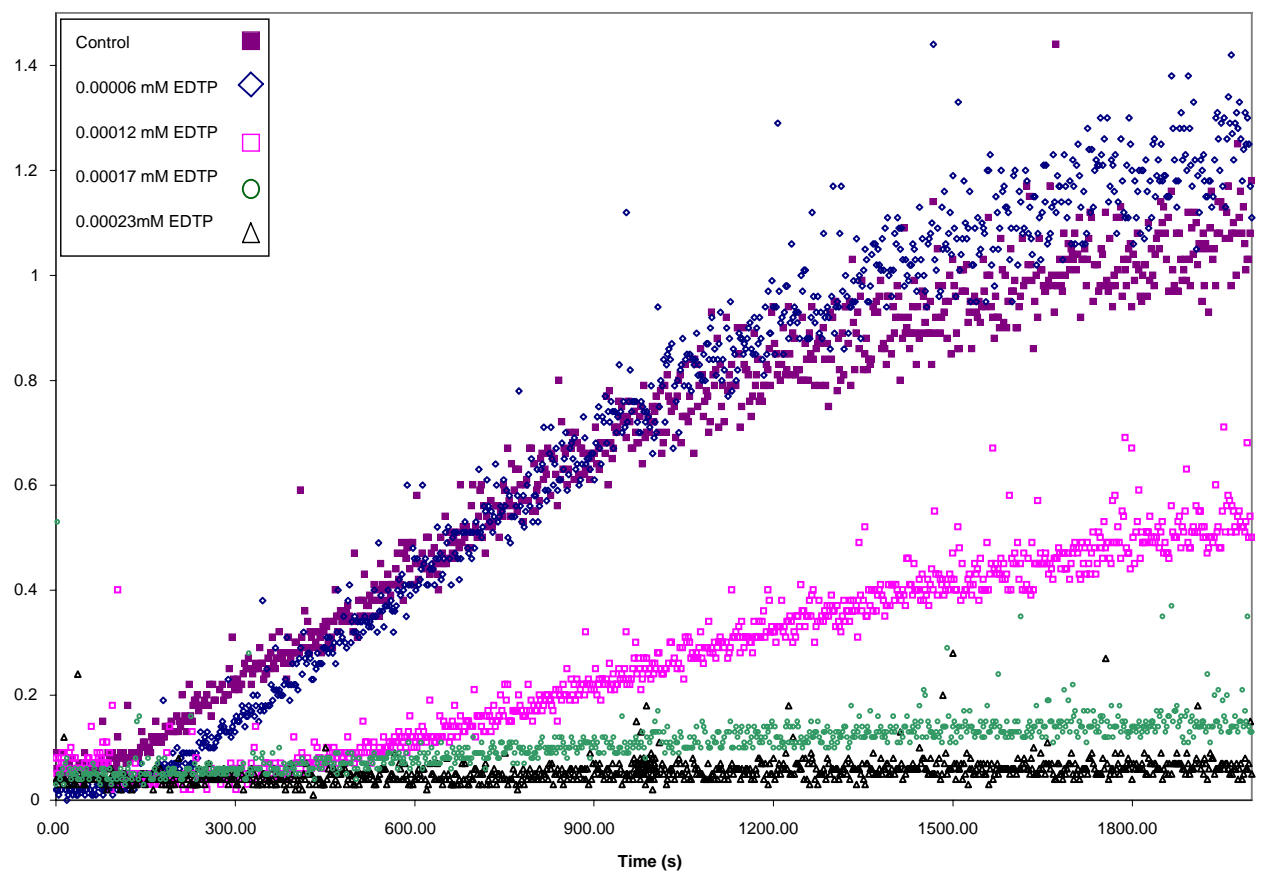

Figure 6. Nephelometry results for barium sulfate precipitated in the presence of EDTP showing a lengthening of the induction time. 
APPENDIX

\section{A}

Barium sulfate potentials

Buckingham

Ba-O

$\mathrm{O}-\mathrm{O}$

Morse

S-O

3-body

$\mathrm{O}-\mathrm{S}-\mathrm{O}$

Charges

$\begin{array}{ll}\mathrm{Ba} & 2.000 \\ \mathrm{~S} & 1.360 \\ \mathrm{O} & -0.8400\end{array}$

$\mathrm{D}_{\mathrm{e}}$

5.000
A $\rho 2 \quad$ C

$4204.794 \quad 0.2907$

$\begin{array}{lll}103585.02 & 0.2000 & 25.98\end{array}$

$\beta$

1.2000

$\mathrm{r}_{\mathrm{o}}$

1.52029

$\theta$

7.15244

\section{B}

Interatomic potentials for describing the interactions between the organic molecule and the barite lattice.

C1 refers to that carbon bonded to the phosphorous atom or carboxylate carbon atom, C2 refers to that carbon on the backbone and C3 refers to the carboxylate carbon. All Lennard-Jones potentials are 9-6 in form.

A

\section{EDTP}

Ba-O $\mathrm{O}_{\text {phos }}$

Ba-P

Ba-C2

Ba-N

Ba-C1

Ba-H1

$\mathrm{S}-\mathrm{O}_{\text {phos }}$

S-P

S-C2

$\mathrm{S}-\mathrm{N}$

S-C1

S-H1
1420

7210

2010

1750

2110

301

2740

1190

3650

3300

3800

688
B

53.9

173.0

64.7

62.4

66.5

16.6

62.2

199.0

74.6

71.9

76.6

19.1 


\begin{tabular}{|c|c|c|}
\hline $\mathrm{O}-\mathrm{O}_{\text {phos }}$ & 673 & 19.8 \\
\hline $\mathrm{O}-\mathrm{P}$ & 3140 & 63.4 \\
\hline O-C2 & 921 & 23.7 \\
\hline $\mathrm{O}-\mathrm{N}$ & 819 & 22.9 \\
\hline O-C1 & 962 & 24.4 \\
\hline O-H1 & 158 & 6.09 \\
\hline \multicolumn{3}{|l|}{ EDTA } \\
\hline Ba-O ${ }_{\text {carb }}$ & 1420 & 53.9 \\
\hline Ba-C3 & 1830 & 61.8 \\
\hline Ba-C1 & 2000 & 64.4 \\
\hline Ba-N & 1650 & 60.8 \\
\hline Ba-C2 & 2000 & 64.5 \\
\hline Ba-H1 & 301 & 16.6 \\
\hline $\mathrm{S}-\mathrm{O}_{\text {carb }}$ & 2740 & 62.2 \\
\hline S-C3 & 3380 & 71.3 \\
\hline S-C1 & 3630 & 74.3 \\
\hline S-N & 3150 & 70.2 \\
\hline S-C2 & 3640 & 74.4 \\
\hline S-H1 & 688 & 19.1 \\
\hline $\mathrm{O}-\mathrm{O}_{\text {carb }}$ & 673 & 19.8 \\
\hline O-C3 & 847 & 22.7 \\
\hline O-C1 & 915 & 23.6 \\
\hline $\mathrm{O}-\mathrm{N}$ & 777 & 22.3 \\
\hline $\mathrm{O}-\mathrm{C} 2$ & 918 & 23.7 \\
\hline O-H1 & 158 & 6.09 \\
\hline
\end{tabular}

\section{Charges}

$\begin{array}{lcc}\text { C1 } & -0.157 & -0.51 \\ \text { C2 } & -0.124 & 0.26 \\ \text { P } & \text { NA } & 2.01 \\ \text { N } & -0.022 & -0.45 \\ \text { H1 } & 0.048 & 0.05 \\ \text { Ophos } & \text { NA } & -1.185 \\ \text { C3 } & 0.436 & \text { NA } \\ \text { Ocarb } & -0.675 & \text { NA }\end{array}$

$\mathrm{NA}=$ not applicable to this molecule 